\title{
Novel 24-h ovine model of brain death to study the profile of the endothelin axis during cardiopulmonary injury
}

\author{
Ryan P. Watts ${ }^{1,4,5^{*}}$ (D) Izabela Bilska ${ }^{1,2}$, Sara Diab ${ }^{1}$, Kimble R. Dunster ${ }^{1,3}$, Andrew C. Bulmer ${ }^{2}$, Adrian G. Barnett ${ }^{3}$
} and John F. Fraser ${ }^{1,3,4}$

\author{
*Correspondence: ryan.watts@ \\ health.qld.gov.au \\ ${ }^{1}$ Critical Care Research Group, The \\ Prince Charles Hospital, Chermside, \\ Queensland, Australia \\ ${ }^{4}$ University of Queensland, Brisbane, \\ Queensland, Australia \\ Full list of author information is \\ available at the end of the article
}

\begin{abstract}
Background: Upregulation of the endothelin axis has been observed in pulmonary tissue after brain death, contributing to primary graft dysfunction and ischaemia reperfusion injury. The current study aimed to develop a novel, 24-h, clinically relevant, ovine model of brain death to investigate the profile of the endothelin axis during brain death-associated cardiopulmonary injury. We hypothesised that brain death in sheep would also result in demonstrable injury to other transplantable organs.

Methods: Twelve merino cross ewes were randomised into two groups. Following induction of general anaesthesia and placement of invasive monitoring, brain death was induced in six animals by inflation of an extradural catheter. All animals were supported in an intensive care unit environment for $24 \mathrm{~h}$. Animal management reflected current human donor management, including administration of vasopressors, inotropes and hormone resuscitation therapy. Activation of the endothelin axis and transplantable organ injury were assessed using ELISA, immunohistochemistry and standard biochemical markers.
\end{abstract}

Results: All animals were successfully supported for $24 \mathrm{~h}$. ELISA suggested early endothelin-1 and big endothelin-1 release, peaking 1 and $6 \mathrm{~h}$ after BD, respectively, but there was no difference at $24 \mathrm{~h}$. Immunohistochemistry confirmed the presence of the endothelin axis in pulmonary tissue. Brain dead animals demonstrated tachycardia and hypertension, followed by haemodynamic collapse, typified by a reduction in systemic vascular resistance to $46 \pm 1 \%$ of baseline. Mean pulmonary artery pressure rose to $186 \pm 20 \%$ of baseline at induction and remained elevated throughout the protocol, reaching $25 \pm 2.2 \mathrm{mmHg}$ at $24 \mathrm{~h}$. Right ventricular stroke work increased $25.9 \%$ above baseline by $24 \mathrm{~h}$. Systemic markers of cardiac and hepatocellular injury were significantly elevated, with no evidence of renal dysfunction.

Conclusions: This novel, clinically relevant, ovine model of brain death demonstrated that increased pulmonary artery pressures are observed after brain death. This may contribute to right ventricular dysfunction and pulmonary injury. The development of this model will allow for further investigation of therapeutic strategies to minimise the deleterious effects of brain death on potentially transplantable organs.

Keywords: Brain death, Organ transplantation, Haemodynamics, Pulmonary circulation, Ventricular Function, Right, Endothelin-1, Receptors, Endothelin, Sheep

\section{Springer}

(c) 2015 Watts et al. Open Access This article is distributed under the terms of the Creative Commons Attribution 4.0 International License (http://creativecommons.org/licenses/by/4.0/), which permits unrestricted use, distribution, and reproduction in any medium, provided you give appropriate credit to the original author(s) and the source, provide a link to the Creative Commons license, and indicate if changes were made. 


\section{Background}

After brain death (BD), the lungs are particularly susceptible to injury in the peri-transplant period secondary to direct trauma, soiling with blood or gastric contents, iatrogenic injury, infection and inflammation [1-3]. Details of the specific mechanisms of catecholamine- and cytokine-induced donor organ injury after BD are yet to be fully elucidated $[2,4,5]$. Peri-transplant injury contributes to the ongoing shortage of transplantable lungs; this is highlighted by American data reporting an average rate of lungs transplanted per donor of 0.37 [6].

Endothelins, their precursors, receptors and associated signalling pathways are collectively referred to as the endothelin axis $[7,8]$. Endothelin-1 (ET-1) is a potent vasoconstrictor, smooth muscle cell and fibroblast mitogen and a stimulator of inflammatory cell infiltration [9-11]. Once released, ET-1 stimulates matrix metalloproteinase (MMP) expression in pulmonary tissue, resulting in protein hydrolysis and interstitial oedema [2, 8]. Our group first demonstrated that the endothelin axis was upregulated after BD in rats, and that this correlated with pulmonary injury [8]. Upregulation of endothelin receptors "primes" the lungs for post-transplant injury [2] and may partly explain the relationship between endothelin expression and primary graft dysfunction that has been observed in human lung allograft recipients [12].

Haemodynamic instability has limited the duration of previous BD animal studies and supportive measures used to extend these models to clinically relevant timeframes are difficult to apply to small animals [13-15]. Interventions utilised in human BD donors, such as fluid or vasoactive agent administration, may have significant effects on genomic expression of inflammatory mediators [16, 17], further limiting the ability of small animal models to replicate comprehensive, modern, intensive care monitoring and management. To begin to address these issues, porcine models have been extended to $24 \mathrm{~h}[18,19]$. Zhai et al. investigated hepatic injury after $\mathrm{BD}$ in BaMa miniature pigs [18]. Although this is a valid extended model, the animals were small compared to humans (average of $25 \mathrm{~kg}$ ), and the use of other clinically relevant interventions, such as vasopressors, inotropes and hormone resuscitation, were not reported. The model published by Sereinigg et al. was developed to more closely reflect clinical experience with BD donors, including the use of vasoactive agents, however this publication did not specifically include a control group for comparison [19].

No animal model can absolutely replicate all aspects of human pathophysiology [20]. For example, controversy exists regarding rodent modelling of human disease, with evidence both supporting and refuting similarities of inflammatory genomic responses to injury between the two species $[16,21]$. Both pigs and sheep have been effectively utilised as large animal models of human pathology, with each offering notable benefits [22, 23]. Ovine models have been highlighted as particularly suitable for investigating human lung disease [17, 23-25]. Furthermore, sheep models have provided detailed insight into the endothelin axis and its contribution to pulmonary haemodynamics, as well as the role of ET-1 in lung inflammation [23, 26-28]. Therefore, based on these considerations, we have developed a 24-h ovine model to investigate the role of the endothelin axis in BD-related pulmonary inflammation. Additionally, the results of comprehensive investigation of the effects of $\mathrm{BD}$ on ovine haemodynamics and systemic markers of transplantable organ injury are presented. 


\section{Methods}

\section{Ethics approval}

This study was conducted with the approval of the Queensland University of Technology Animal Ethics Committee, approval number 0900000319. All experiments were performed in accordance to NHMRC Australian Code of Practice for the Care and Use of Animals for Scientific Purposes and the Animal Care and Protection Act 2001 (QLD).

\section{Animal management}

Twelve merino cross ewes were randomly allocated to groups of six animals each (BD vs control) using Statmate (GraphPad Software, La Jolla, CA). Initial surgical preparation was the same in all animals. A comprehensive description of the animal management protocol can be found in Additional file 1, whilst Table 1 lists the details of the medications used in this study. After fasting, the external jugular veins were cannulated, general anaesthesia was induced with midazolam and alfaxalone, and all animals were intubated. Pulmonary arterial and peripheral arterial catheters were placed. Intracranial access was obtained through a burr-hole midway between the midline and lateral edge of the cranium, rostral to the animal's horn base, and an intracranial pressure monitor was introduced. This was designated as the protocol start time (PST) in non-BD animals.

Another burr hole was created on the contralateral side in animals allocated to BD, followed by the extradural placement of a 16 Fr Foley catheter. Brain death was induced by normal saline inflation of the catheter to increase intracranial pressure (ICP) above the mean arterial pressure (MAP) for greater than $30 \mathrm{~min}$ [29]. Commencement of inflation served as the BD induction time (BIT). Confirmation of brain death was achieved by continuously negative cerebral perfusion pressure (defined as MAPICP) for greater than $30 \mathrm{~min}$, loss of pupillary and corneal reflexes and lack of respiratory efforts. Protocol start time was deemed once BD was confirmed in animals allocated to this group. Due to variability in duration required for induction and confirmation of $\mathrm{BD}$, haemodynamic results are reported as time from BIT. Haemodynamic deterioration was managed with intravenous fluid and vasopressors or inotropes as appropriate.

Twelve hours after PST, hormone therapy was commenced with vasopressin, methylprednisolone and liothyronine in all animals. This time point was chosen to reflect the clinical realities of delays in diagnosis and confirmation of brain death, family consent for organ transplantation, and the change from lifesaving to organ preserving treatment [30]. After completion of the 24-h protocol, the animals were sacrificed using sodium pentobarbitone.

\section{Sample retrieval and storage}

Blood was collected from the peripheral arterial line at baseline (prior to BIT), 1, 6, 12, 18 and $24 \mathrm{~h}$ after confirmation of BD. Blood samples were then centrifuged, supernatant transferred into vials (Eppendorf, North Ryde, Australia) and stored at $-80{ }^{\circ} \mathrm{C}$ until analysis. After animals were euthanised, the lungs were removed en bloc and samples taken from both lower lobes. These were fixed in $10 \%$ phosphate-buffered formalin, embedded in paraffin and mounted on slides for histological analysis. 
Table 1 Medications for the protocol

\begin{tabular}{|c|c|c|c|}
\hline Drug & Bolus & Initial infusion rate & Notes \\
\hline \multicolumn{4}{|c|}{ Anaesthetic induction } \\
\hline Lignocaine $1 \%$ & $\begin{array}{l}3-5 \mathrm{~mL} \\
\text { subcutaneously }\end{array}$ & & $\begin{array}{l}\text { Over central venous access } \\
\text { insertion sites }\end{array}$ \\
\hline Buprenorphine & 300 mcg & & $\begin{array}{l}\text { Administered six hourly during } \\
\text { protocol }\end{array}$ \\
\hline Midazolam & $0.5 \mathrm{mg} / \mathrm{kg}$ & & \\
\hline Alfaxalone & 3 mg/kg & & $\begin{array}{l}\text { If further boluses needed, dosed at } \\
0.5 \mathrm{mg} / \mathrm{kg}\end{array}$ \\
\hline
\end{tabular}

Anaesthetic maintenance

Alfaxalone

Ketamine

Midazolam

Antimicrobial prophylaxis

$\begin{array}{ll}\text { Cefalotin } & 1000 \mathrm{mg} \\ \text { Gentamicin } & 40 \mathrm{mg}\end{array}$

Fluid management

Hartmann's solution

$10-20 \mathrm{~mL} / \mathrm{kg} \quad 2 \mathrm{~mL} / \mathrm{kg} / \mathrm{h}$

Normal saline $0.9 \%$

$10-20 \mathrm{~mL} / \mathrm{kg} \quad 1-2 \mathrm{~mL} / \mathrm{kg} / \mathrm{h}$

Dextrose $5 \%$ or dextrose

$4 \%$ in saline $0.18 \%$

$10-20 \mathrm{~mL} / \mathrm{kg} \quad 1-2 \mathrm{~mL} / \mathrm{kg} / \mathrm{h}$

Vasopressors, inotropes and cardiovascular support

$\begin{array}{ll}\text { Metaraminol } & 0.5-1 \mathrm{mg} \\ \text { Atropine } & 600 \mathrm{mcg}\end{array}$

Noradrenaline

Dopamine

Isoprenaline

Glyceryl trinitrate

Amiodarone

Hormonal management
Insulin
$10-20 \mathrm{U}$
$0.5 \mathrm{U} / \mathrm{h}$

$25 \mathrm{~mL}$

Desmopressin

$$
\begin{aligned}
& 6 \mathrm{mg} / \mathrm{kg} / \mathrm{h} \\
& 3 \mathrm{mg} / \mathrm{kg} / \mathrm{h} \\
& 0.25 \mathrm{mg} / \mathrm{kg} / \mathrm{h}
\end{aligned}
$$

Adjusted to surgical plane

Adjusted to surgical plane

Used only if required

(if alfaxalone exceeded $250 \mathrm{mg} / \mathrm{h}$ )
Titrated to CVP 8-12 mmHg. Boluses if needed for low urine output $(<0.5 \mathrm{~mL} / \mathrm{kg} / \mathrm{h})$ or hypotension (MAP $<60 \mathrm{mmHg}$ ). Initial fluid of choice

Boluses if needed for low urine output (UO $<0.5 \mathrm{~mL} / \mathrm{kg} / \mathrm{h}$ ) or hypotension (MAP $<60 \mathrm{mmHg}$ )

Utilised for hypoglycaemia (BSL < $6 \mathrm{mmol} / \mathrm{L})$

Utilised in emergency situations for hypotension only

Utilised in emergency situations for bradycardia ( $\mathrm{HR}<60$ bpm) only

Adjusted to MAP > $60 \mathrm{mmHg}$

$5 \mathrm{mcg} / \mathrm{kg} / \mathrm{min}$

$0.5 \mathrm{mcg} / \mathrm{min}$

$0.1 \mathrm{mg} / \mathrm{h}$

$5 \mathrm{mg} / \mathrm{kg}$ over $2 \mathrm{~h}$

Adjusted to MAP $>60 \mathrm{mmHg}$

Adjusted to MAP > 60 and $H R>60 \mathrm{bpm}$. Utilised only if considered bradycardia as cause of hypotension

For hypertension (SBP > $180 \mathrm{mmHg}$ ) if necessary

Infusion for appropriate dysrhythmias (e.g. atrial fibrillation) if necessary. Could be repeated

Bolus for BSL > $16 \mathrm{mmol} / \mathrm{L}$. Infusion adjusted to BSL 6-10 $\mathrm{mmol} / \mathrm{L}$, tested hourly once infusion commenced

For management of hypoglycaemia (BSL $<3.5 \mathrm{mmol} / \mathrm{L}$ ). Please also note that dextrose $5 \%$ could be used for ongoing maintenance per above

If urine output $>300 \mathrm{~mL} / \mathrm{h}$ for two consecutive hours 
Table 1 Medications for the protocol (Continued)

\begin{tabular}{|c|c|c|c|}
\hline \multicolumn{4}{|c|}{ Hormone resuscitation at $12 \mathrm{~h}$} \\
\hline Vasopressin & $1 U$ & $\begin{array}{l}0.5-4.0 \mathrm{U} / \mathrm{h} \\
\text { (initial dose } 2.0 \mathrm{U} / \mathrm{h} \text { ) }\end{array}$ & Adjusted to SVR 800-1200 dyn.s.cm ${ }^{-5}$ \\
\hline Liothyronine & $4 \mathrm{mcg}$ & $3 \mathrm{mcg} / \mathrm{h}$ & \\
\hline Methylprednisolone & $15 \mathrm{mg} / \mathrm{kg}$ & & \\
\hline \multicolumn{4}{|l|}{ Electrolyte management } \\
\hline Potassium chloride & & $10-40 \mathrm{mmol} / \mathrm{h}$ & Adjusted to potassium $3.5-5.0 \mathrm{mmol} / \mathrm{L}$ \\
\hline Calcium chloride $10 \%$ & $6.8 \mathrm{mmol}$ & & $\begin{array}{l}\text { Administered to keep ionised } \\
\text { calcium }>1.05 \mathrm{mmol} / \mathrm{L}\end{array}$ \\
\hline Magnesium sulphate & 10-20 mmol & & $\begin{array}{l}\text { Allowed for management of } \\
\text { dysrhythmias (e.g. atrial fibrillation) }\end{array}$ \\
\hline \multicolumn{4}{|l|}{ Euthanasia } \\
\hline Sodium pentobarbitone & 100 mg/kg & & \\
\hline
\end{tabular}

Not all agents were used. Agents listed include medications that were able to be used in the case of predetermined outcomes or complications

\section{Histological and tissue analysis}

Samples were taken from the right lower lobe to assess for wet:dry weight ratio, as an indicator of inflammatory oedema. These were dehydrated in an oven at $45^{\circ} \mathrm{C}$ for $48 \mathrm{~h}$, at which time they were reweighed and the ratio calculated.

Haematoxylin and eosin staining of lung specimens was performed to allow morphologic assessment of tissue samples. Inflammation was graded semi-quantitatively as previously reported [8].

Immunohistochemical staining was employed to assess the patency of the endothelin axis using standard methods (see also Additional file 1) [31]. Monoclonal anti-ET-1 (Sigma Aldrich, St Louis, MO), polyclonal anti-ET $\mathrm{R}_{\mathrm{R}} \mathrm{A}$, anti-ET $\mathrm{R}_{\mathrm{R}} \mathrm{B}$ and anti-MMP-2 (Merck Millipore, Billerica, MA), polyclonal anti-MMP-9 (Biorbyt, San Francisco, CA) and polyclonal anti-TIMP-1 (tissue inhibitor of metalloproteinase-1) and anti-TIMP-2 (Bioss, Woburn, MA) were selected as primary antibodies.

Immunohistochemistry and histological scoring was performed independently by two investigators (RW and IB) and results compared. Disagreements in scoring were resolved by using the lowest score (i.e. indicating less injury). Slides were assessed in random order and the assessors were blinded to group of allocation.

\section{ELISA}

Systemic concentrations of ET-1 and pro-endothelin-1 (big ET-1) were assessed in EDTA plasma using commercially available sandwich ELISA kits (BiomedicaGruppe, Austria). Absorbance was read at $450 \mathrm{~nm}$ with reference $630 \mathrm{~nm}$ on a 96-well plate spectrophotometer (FluoStar Omega, BMG LabTech, Germany). The results from one animal in the BD group were excluded due to technical reasons preventing accurate spectrophotometric analysis.

\section{Biochemical analysis}

Biomarkers of organ injury were assayed using the COBAS Integra 400 chemical analyser (Roche Diagnostics, Dee Why, Australia), following manufacturer's instructions. 
Reagent cassettes were calibrated using the calibrator for automated systems (CFAS, Roche Diagnostics). Precision and accuracy of assays were confirmed using standard quality controls (Precinorm Clin Chem Multi 1 and 2, Roche Diagnostics). All tests were performed in duplicate, averaged and compared to CFAS in order to interpolate sample concentrations.

\section{Statistical analysis}

Analysis of biochemical data was performed using Prism 6 (GraphPad Software Inc., USA). All regression analyses were conducted using $\mathrm{R}$ software (www.r-project.org). A two-sided statistical significance level of $<0.05$ was adopted. Results are reported as mean \pm standard deviation. Two-way repeated-measures analysis of variance (ANOVA) was used to test for significant differences in dependent variables. Student's $t$ test was used to compare changes in physiological variables at specified time points. Fisher's exact test was used to compare semi-quantitative assessment of tissue samples. For continuous physiological variables, a regression model was used to examine the changes in variables over time. A mixed model with a random intercept for each sheep to account for repeated responses from the same animal was used [32].

\section{Results}

All 12 animals survived the 24-h protocol and induction of BD was successful in all animals allocated to this group. Summary tables detailing ventilation, haemodynamics, fluid balance, biochemistry and histology can be found in Additional file 1.

\section{Animal management and point of care testing}

There were no differences between the animal groups with regard to mechanical ventilation. Markers of oxygenation, $\mathrm{P}(\mathrm{A}-\mathrm{a}) \mathrm{O}_{2}$ and $\mathrm{PaO}_{2}: \mathrm{FiO}_{2}$, deteriorated in $\mathrm{BD}$ animals over the first $2 \mathrm{~h}$. Mean $\mathrm{P}(\mathrm{A}-\mathrm{a}) \mathrm{O}_{2}$ in $\mathrm{BD}$ animals was $145 \pm 79 \mathrm{mmHg}(19.3 \pm 105 \mathrm{kPa})$ at $1 \mathrm{~h}(66.8 \pm 40 \mathrm{mmHg}(8.9 \pm 5.3 \mathrm{kPa}, p<0.001)$ greater than controls $)$ and $87 \pm$ $45 \mathrm{mmHg}(11.5 \pm 5.9 \mathrm{kPa})$ at $2 \mathrm{~h}(45.7 \pm 40 \mathrm{mmHg}(6.09 \pm 5.3 \mathrm{kPa}, p=0.016)$ greater than controls). $\mathrm{PaO}_{2}: \mathrm{FiO}_{2}$ was $221 \pm 81$ less in $\mathrm{BD}$ animals (absolute value $294 \pm 83$, $p<0.001$ ) at $1 \mathrm{~h}$ and $110 \pm 80$ less at $2 \mathrm{~h}$ (absolute value $432 \pm 114, p=0.003$ ). These variables were thereafter similar to controls and no difference was found at $24 \mathrm{~h}(p$ $=0.56 \mathrm{P}(\mathrm{A}-\mathrm{a}) \mathrm{O}_{2}$ and $\left.p=0.87 \mathrm{PaO}_{2}: \mathrm{FiO}_{2}\right)$. Minute ventilation was similar between the groups, with a trend towards lower $\mathrm{PaCO}_{2}$ in the control group at $24 \mathrm{~h}\left(\mathrm{PaCO}_{2} 27 \pm\right.$ $4 \mathrm{mmHg}(3.6 \pm 0.5 \mathrm{kPa})$ control vs $32 \pm 5 \mathrm{mmHg}(4.3 \pm 0.6 \mathrm{kPa}) \mathrm{BD}, p=0.051)$. Lactate, a surrogate marker of hypoperfusion, was significantly elevated in the $\operatorname{BD}$ group $(p=0.03)$, reaching a peak value of $2.75 \pm 3.3 \mathrm{mmol} / \mathrm{L}$ at $18 \mathrm{~h}$. There was no difference in blood $\mathrm{pH}$ between groups $(p=0.85)$. No vasoactive agents were required in the control group, whereas all $\mathrm{BD}$ animals required vasoactive support (Fig. 1). Each of the six BD animals met predefined criteria for diabetes insipidus and required desmopressin. Although BD animals therefore had greater urine output and fluid administration, cumulative fluid balance at $24 \mathrm{~h}$ was not different between groups $(2.1 \pm 0.8 \mathrm{~L}$ control vs $2.4 \pm 1.7 \mathrm{~L} \mathrm{BD}, p>0.9)$.

\section{Physiologic variables}

Time to confirmation of brain death after inflation of the extradural catheter was $50 \pm$ $22 \mathrm{~min}$. During this time, the highest ICP achieved was $237 \pm 79 \mathrm{mmHg}$, with a 


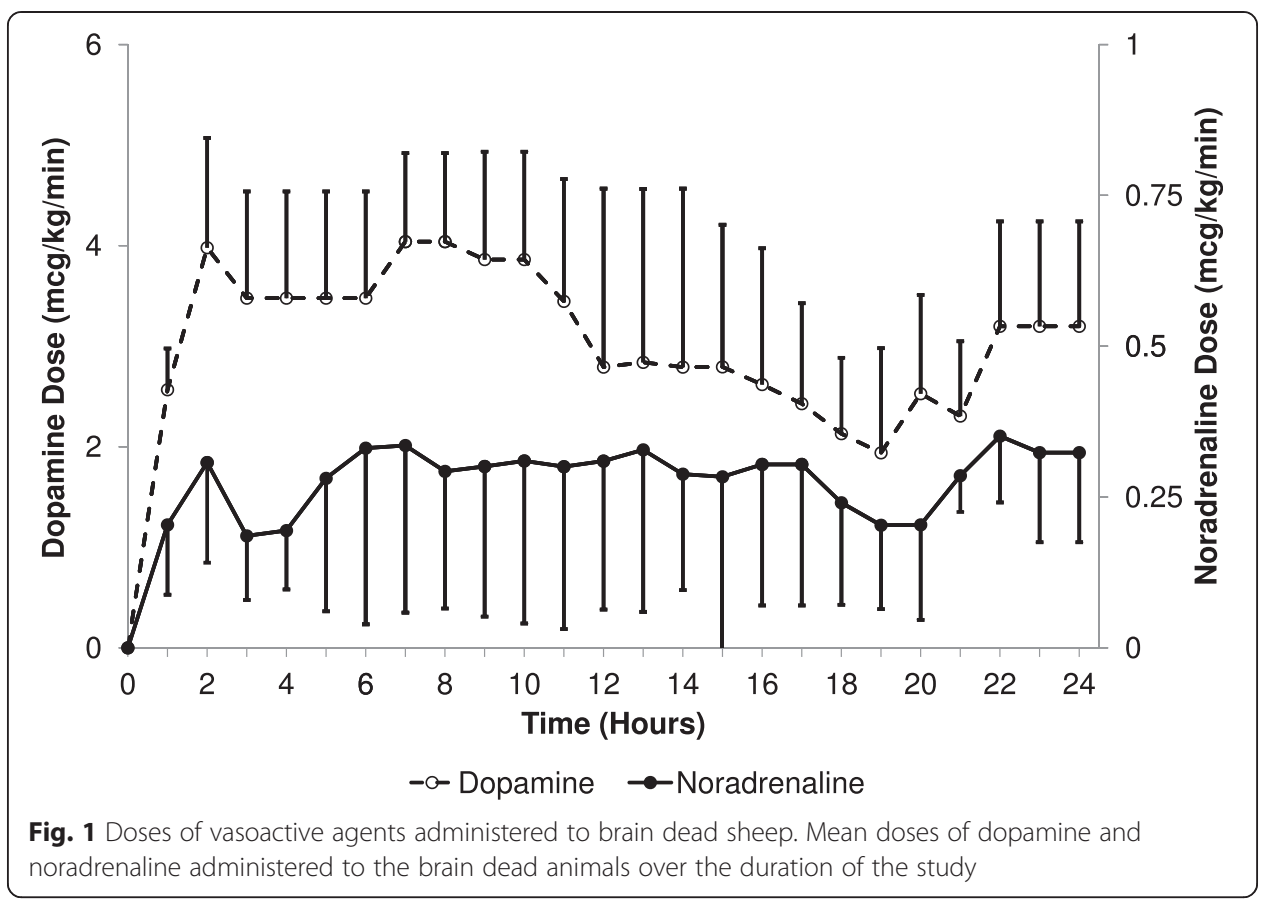

resultant CPP of $-117 \pm 34 \mathrm{mmHg}$. At completion of the study, ICP was $87 \pm 12 \mathrm{mmHg}$ with a CPP of $-6.5 \pm 12 \mathrm{mmHg}$.

Brain death caused tachycardia, hypertension and elevated cardiac output (Fig. 2a-c). Cardiac index (CI) increased primarily as a consequence of tachycardia with the stroke volume index (SVI) acutely decreasing from $45 \pm 1$ to $30 \pm 6 \mathrm{~mL} / \mathrm{m}^{2}(p<0.001)$. Mean arterial pressure increased from $99 \pm 3 \mathrm{mmHg}$ to peak at $193 \pm 40 \mathrm{mmHg}$ during induction of $\mathrm{BD}$, decreasing to $58 \pm 2 \%$ of baseline at $90 \mathrm{~min}$ after $\operatorname{BIT}(p<0.001)$ and remaining lower than the control group at $24 \mathrm{~h}(p<0.001)$. Systemic vascular resistance index (SVRI-Fig. 2d) increased from 1741 to 3718 dyn.s.cm ${ }^{-5}$ within 5 min of extradural catheter inflation, falling to $46 \pm 1 \%$ of baseline by $1 \mathrm{~h}$ and remaining depressed throughout the remainder of the study. After initiation of hormone resuscitation, SVRI increased to $81 \pm 7 \%$ of baseline. Cardiac index increased to a peak of $7.48 \pm 2.1 \mathrm{~L} /$ $\mathrm{min} / \mathrm{m}^{2}$ from a baseline of $4.55 \pm 0.18 \mathrm{~L} / \mathrm{min} / \mathrm{m}^{2} 30 \mathrm{~min}$ after BIT and remained $14 \pm$ $5 \%$ above baseline until $1 \mathrm{~h}$ after hormonal therapy was commenced, whereby it returned to baseline levels. At $24 \mathrm{~h}$, there was no statistical difference ( $p=0.79$ compared to baseline, $p=0.91$ compared with controls). Left ventricular stroke work index (LVSWI) was significantly reduced in BD animals compared to controls $(p<0.001)$. After decreasing to $19.8 \pm 0.69 \mathrm{~g} . \mathrm{m} / \mathrm{m}^{2} /$ beat at $75 \mathrm{~min}$ post-BIT, LVSWI returned to $35.1 \pm 1.3$ g.m $/ \mathrm{m}^{2} /$ beat over the following $4 \mathrm{~h}$. Hormonal resuscitation therapy increased LVSWI to $44.8 \pm 2.8 \mathrm{~g} \cdot \mathrm{m} / \mathrm{m}^{2} /$ beat at $24 \mathrm{~h}(p<0.001$ compared to baseline).

Mean pulmonary artery pressure (mPAP) peaked at $186 \pm 20 \%$ of baseline with induction of $\mathrm{BD}(p<0.001)$, rising from $16 \pm 0.2$ to $30 \pm 13 \mathrm{mmHg}$. After the initial peak, mPAP remained $31 \pm 2 \%$ greater than baseline 90 min after $\operatorname{BIT}(p<0.001)$ and continued to increase for the remainder of the experiment (Fig. 3a, b). Pulmonary vascular resistance index (PVRI) increased from $50 \pm 3$ to $123 \pm 77$ dyn.s.cm ${ }^{-5}$ within 5 min of Foley catheter inflation (Fig. 3c), decreasing to $55 \pm 4 \%$ of baseline at $4 \mathrm{~h}$ after BD. The 


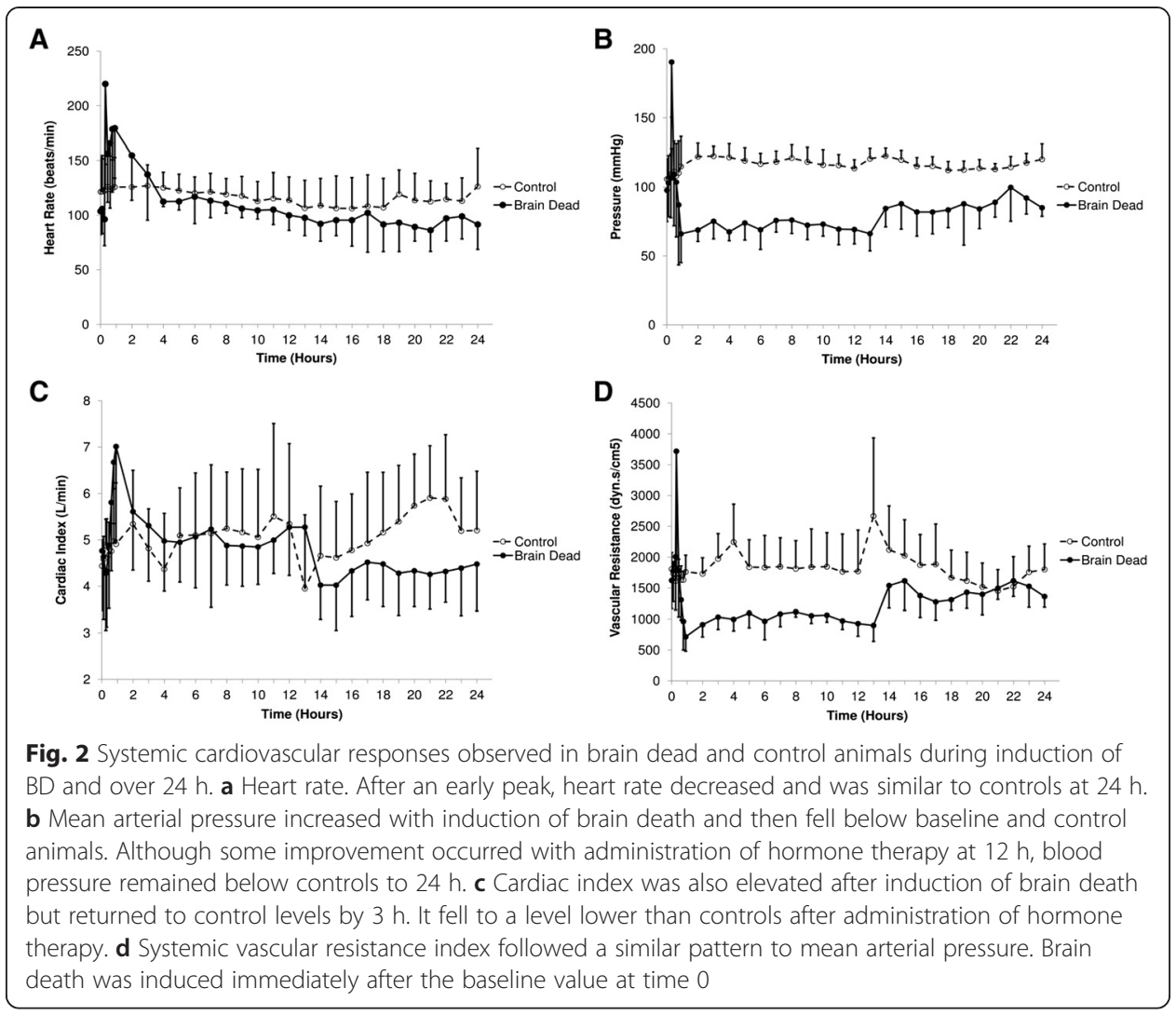

PVRI returned to baseline after initiation of hormone resuscitation and was not different from the control group at $24 \mathrm{~h}(p=0.5)$. Right ventricular stroke work index (RVSWI) had decreased $15 \mathrm{~min}$ after BIT (by $1.4 \pm 0.7 \mathrm{~g} . \mathrm{m} / \mathrm{m}^{2} /$ beat, $p<0.001$ ). However, by $30 \mathrm{~min}$, this had increased to be $5.4 \pm 0.01 \%$ above the baseline of $6.5 \pm$ $0.24 \mathrm{~g} \cdot \mathrm{m} / \mathrm{m}^{2} /$ beat $(p=0.01)$ and continued to increase to $25.9 \%$ above baseline at the end of the study in the BD animals $(p<0.001)$.

\section{Histological and tissue analysis}

There was no statistically significant difference in lung wet:dry ratio between groups, with an average ratio of 3.48 vs 3.39 (non-BD vs $\mathrm{BD}, p=0.68$ ).

Semi-quantitative assessment of lower lobe pulmonary samples demonstrated increased inflammation in BD animals (non-BD animals: none-mild inflammation $(0$ or +$)$; BD animals: moderate-severe inflammation changes $(++$ or +++$)$, including increased interstitial oedema and inflammatory cell infiltration, $p=0.014$ ).

The endothelin axis was detectable by immunohistochemical staining (examples can be found in Additional file 1). Staining of ET-1 was localised to bronchiolar epithelium and perivascular smooth muscle in both BD and non-BD animals, with no appreciable difference in expression noted. With regard to the endothelin receptors, $\mathrm{ET}_{\mathrm{R}} \mathrm{A}$ was stained minimally in both groups within bronchiolar epithelium and smooth muscle, and $\mathrm{ET}_{\mathrm{R}} \mathrm{B}$ was well localised to airway columnar epithelium. There was no difference in expression of either receptor between groups. Overall, there were no differences in intensity of staining for MMP-2 or MMP-9 between groups, with MMP-2 slightly 
A

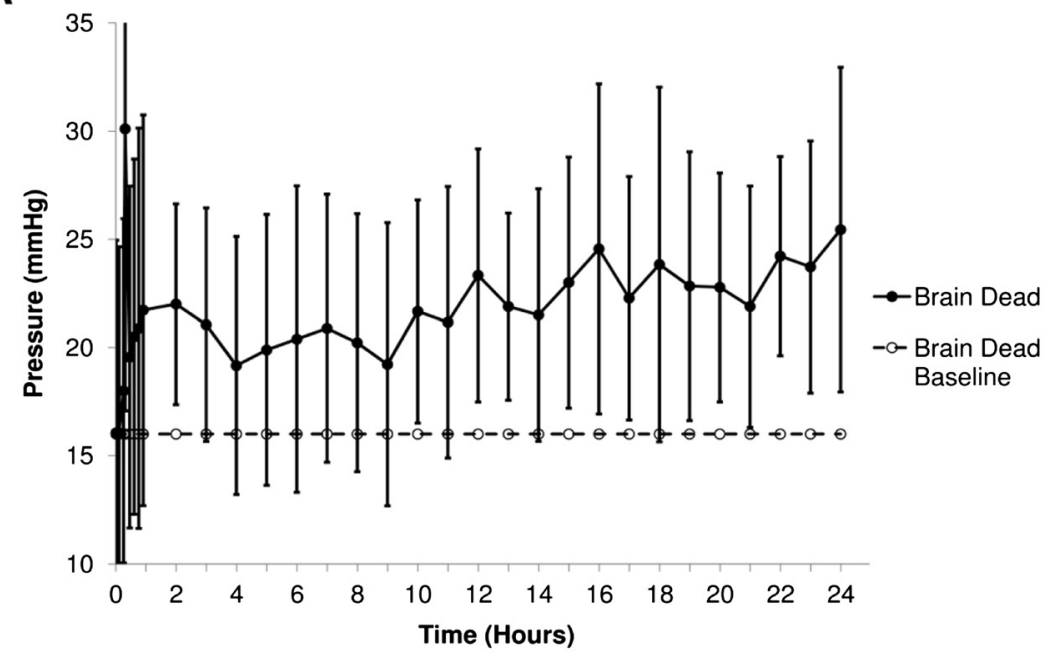

B

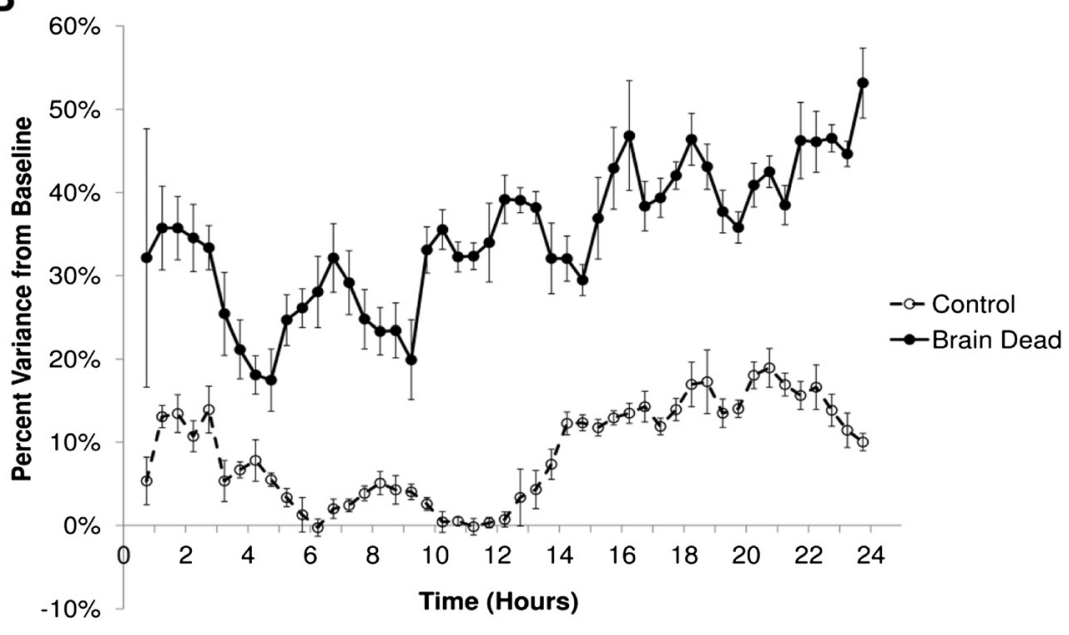

C

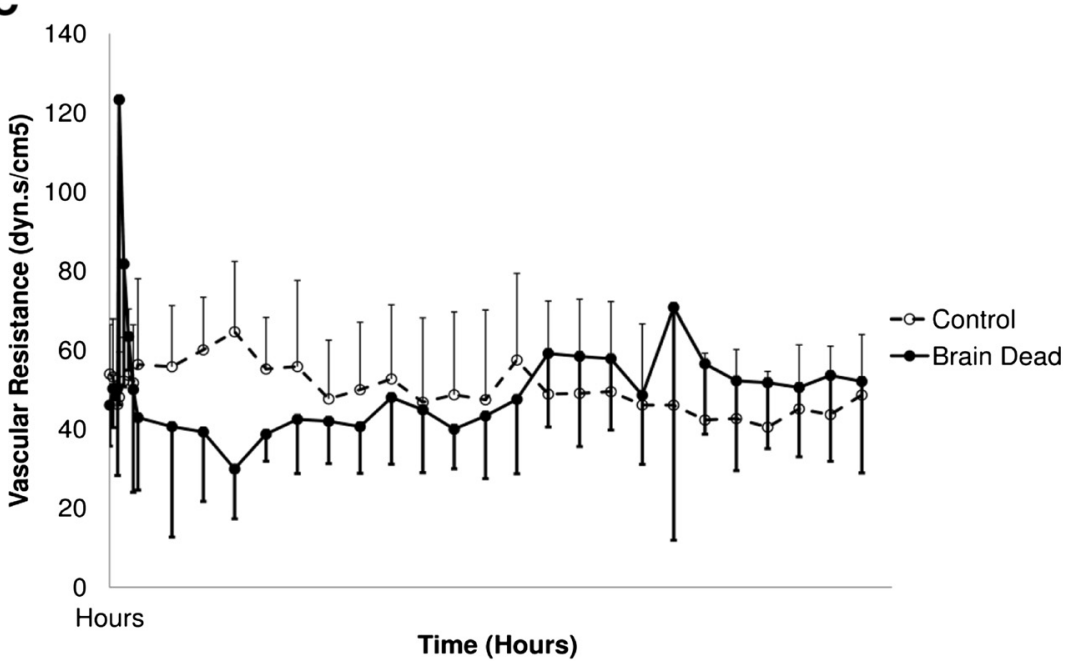

Fig. 3 (See legend on next page.) 
(See figure on previous page.)

Fig. 3 Pulmonary haemodynamic responses observed in brain dead and control animals during induction of BD and over $24 \mathrm{~h}$. a Mean pulmonary arterial pressure peaked early after induction of brain death, increasing over the duration of the study. $\mathbf{b}$ Percent variance from baseline of mean pulmonary artery pressure demonstrates that this deviated to a greater degree over time than control animals. c Pulmonary vascular resistance index also demonstrated an early peak and had returned to levels consistent with controls by $24 \mathrm{~h}$. Brain death was induced immediately after the baseline value at time 0

expressed within vascular endothelial and bronchiolar epithelial cells and MMP-9 able to be identified within bronchiolar epithelium and perivascular smooth muscle.

Low intensity of staining for TIMP-1 and -2 was observed for both groups, with no detectable difference. Staining of TIMP-1 was primarily localised within the columnar epithelia in the bronchioles with some staining within the alveolar parenchyma. Similarly to TIMP-1, TIMP-2 expression was mainly observed in bronchiolar epithelia, though some staining in the alveolar parenchyma and pulmonary blood vessels was noted.

\section{ELISA}

Big ET-1 increased in BD sheep $6 \mathrm{~h}$ after PST compared to baseline ( $p=0.002$, Fig. 4a). Big ET-1 concentrations also tended to be increased compared to control animals at the same time point $(p=0.064)$. After this early peak, concentrations of big ET-1 returned to baseline at $12 \mathrm{~h}$ and remained similar to the non-BD group during the remainder of the protocol ( $p=0.99$ at $24 \mathrm{~h}$ ). Similarly, ET-1 levels rose by $26.9 \%$ from baseline at $1 \mathrm{~h}$ after induction of brain death, approaching statistical significance $(p=0.09$, Fig. $4 \mathrm{~b})$ and then declined to be equivalent to control animals at $12 \mathrm{~h}$. Scatterplots indicated no correlation between hourly average doses of administered vasoactive agents and the observed levels of big ET-1 or ET-1 (Fig. 5).

\section{Biochemical analysis}

Circulating myoglobin and CK-MB increased over time in BD animals (Fig. 6), indicating myocardial necrosis; no change was observed in control animals. In BD animals, myoglobin levels increased earlier than CK-MB, however this did not reach statistical significance compared to control animals ( $p=0.13$ at $24 \mathrm{~h}$ ). CK-MB was significantly elevated in $\mathrm{BD}$ compared to control animals at $24 \mathrm{~h}(p=0.04)$. Hepatic injury was also evident at $24 \mathrm{~h}$ with elevation of both alanine aminotransferase and aspartate aminotransferase in $\mathrm{BD}$ animals $(p<0.001$ for both). Cholestatic enzymes were not elevated, indicating preferential hepatocellular injury. No evidence of renal dysfunction was indicated by elevated creatinine or urea levels ( $p=0.5$ creatinine, $p=0.8$ urea, BD vs control animals at $24 \mathrm{~h}$ ).

\section{Discussion}

This is the first report to document a 24-h, clinically relevant, ovine model of brain death and assess systemic and pulmonary endothelin expression. Histological analysis indicated increased inflammation in the BD lung tissue, consistent with previous literature $[1,8]$. The components of the endothelin axis were identifiable by immunohistochemical staining, with no demonstrable difference found between groups. This is in contradistinction to previous observations in rodents [8]. ELISA did suggest an early 


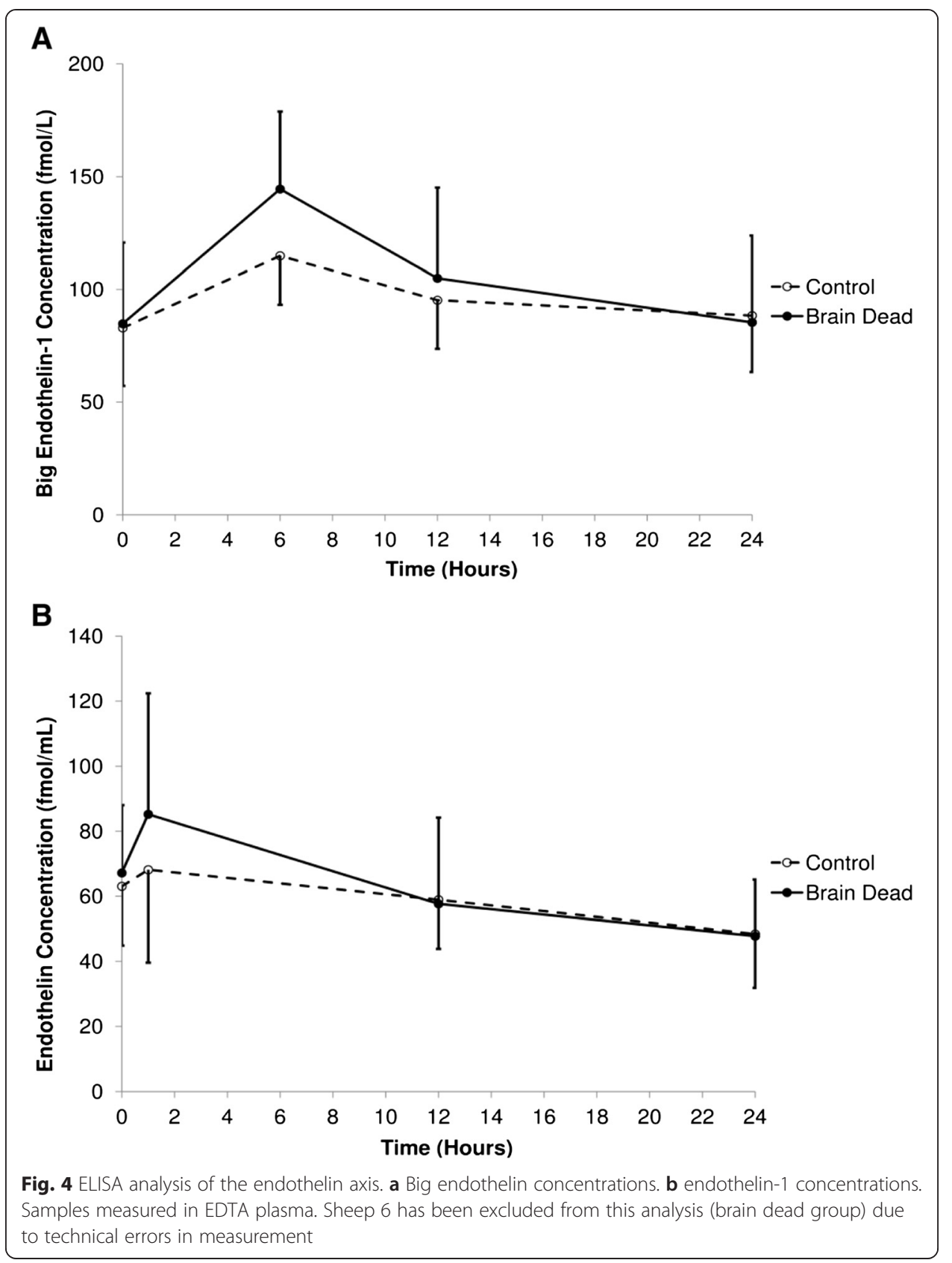

elevation and then resolution of both ET-1 and big ET-1 in plasma after brain death; this may reflect an early release with rapid clearance [33], however no ongoing systemic expression was detected. Observed peak concentrations obtained at 1 and $6 \mathrm{~h}$ for ET-1 and big ET-1, respectively, may reflect significant peaks that occurred earlier but were not captured by the sampling time in this study. Oishi et al. previously demonstrated that ET-1 peaks as early as $30 \mathrm{~min}$ in BD canines, however this elevation was still detectable at $60 \mathrm{~min}$ [14]. Another complicating factor in comparing these results to the current study is the nature of sampling; whilst Oishi's group sampled coronary venous sinus blood (to detect cardiac generated ET-1), our study analysed arterial blood. Systemic levels of ET-1 indicate a spillover effect [34] and therefore may only be detectable 


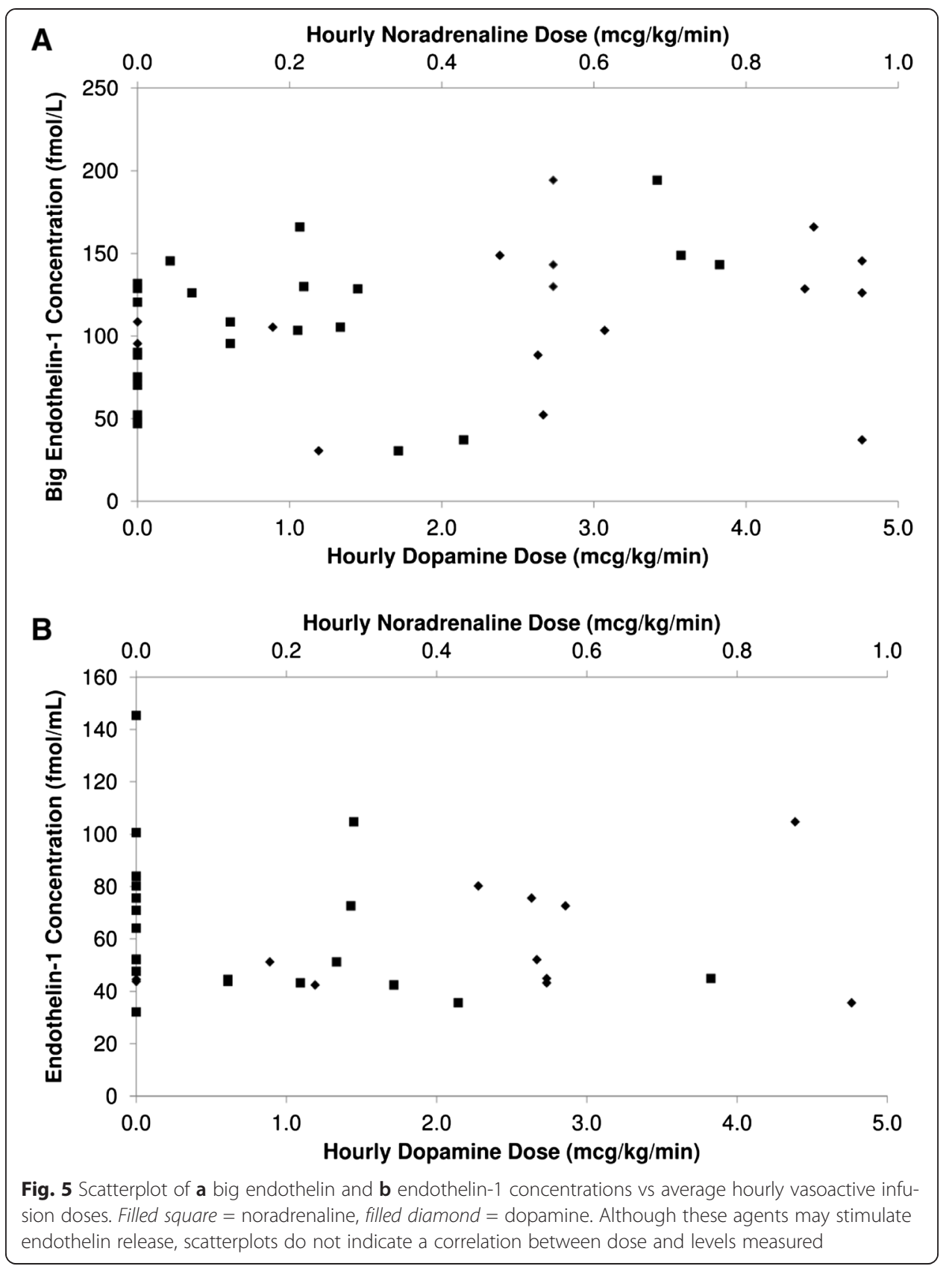

in very low concentrations when assessed in this manner due to mixing of blood returning to the pulmonary circulation. Secondly, pulmonary $\mathrm{ET}_{\mathrm{R}} \mathrm{B}$ may continue to serve its usual function of clearing circulating ET-1, concealing any detectable elevations in mixed central venous blood [35]. Both of these factors may have contributed to our observed results and provide opportunities for future study.

Data is accumulating of the role of ET-1 in brain death and organ donation; activation of the endothelin axis has been demonstrated early in BD-related pulmonary inflammation [8], it contributes to complications associated with human lung donation $[12,36,37]$ and it may contribute to the altered cardiopulmonary haemodynamics observed in the current study, similar to other forms of pulmonary hypertension. As a 


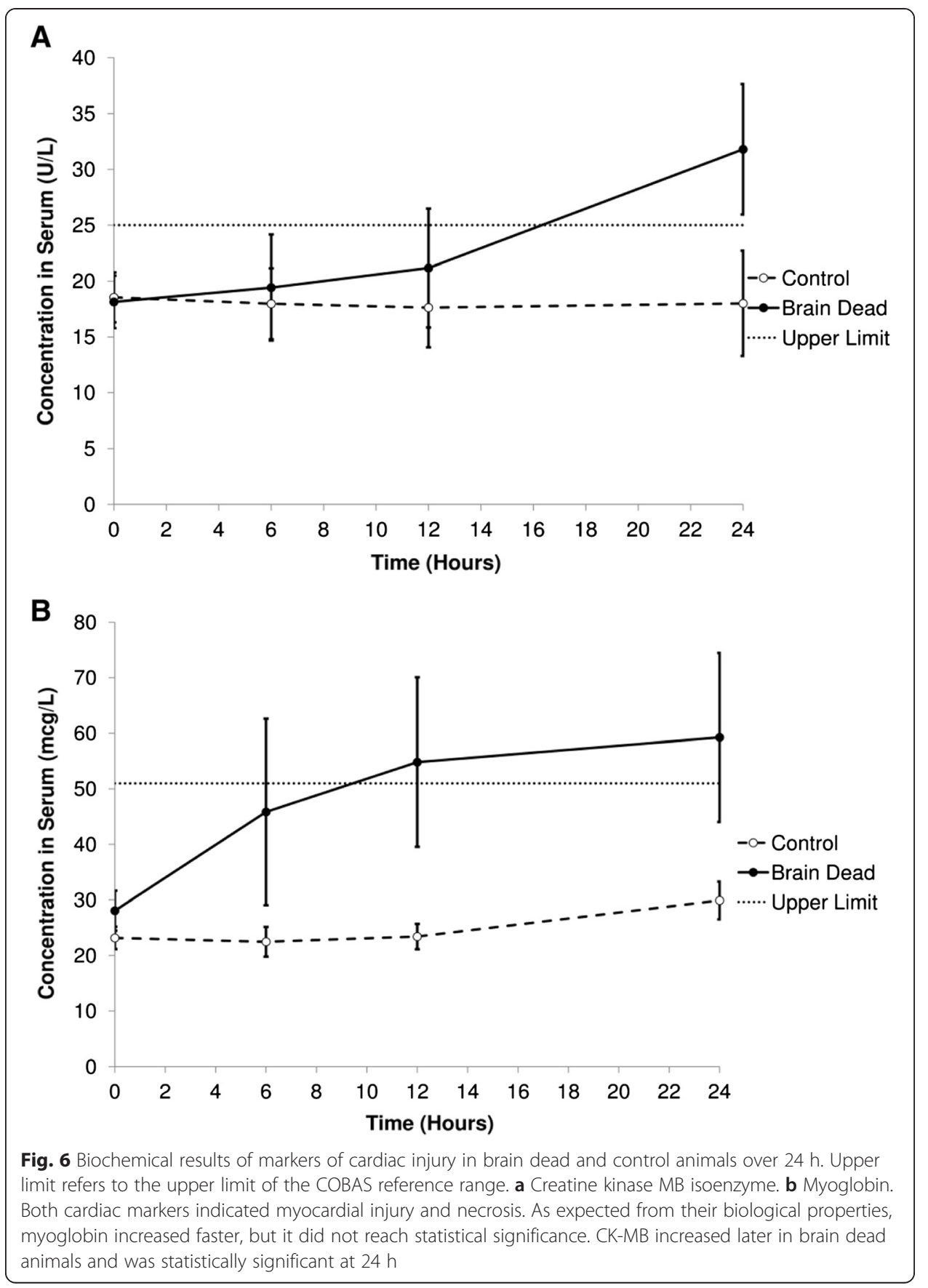

potent mitogen, ET-1 stimulates smooth muscle hyperplasia and leads to airway remodelling and oedema [11]. Furthermore, ET-1-initiated cell signalling leads to shortand long-term injury, fibrosis and, ultimately, allograft rejection [36]. Thus, endothelin1 may induce an inflammatory response that continues to manifest itself long after any detectable elevations in plasma concentrations have resolved. Inflammatory cells recruited to the lung by endothelin signalling and increased ET-1 receptors in allograft tissue [8] may be further activated after transplant by ischemia reperfusion injury [11] and the inflammatory state of the recipient [2]. 
Activation of the sympathetic nervous system during brain death results in dramatic increases in vascular resistance and arterial pressure and contributes to systemic inflammation [38]. Novitzky et al. observed that the resulting increase in SVRI and left atrial pressure leads to transfer of up to $72 \%$ of total blood volume to the lower resistance pulmonary vasculature; mPAP and PVRI were also noted to increase with induction of BD [29]. This has been hypothesised to contribute to pulmonary capillary injury after BD. Bittner and colleagues demonstrated that, when observed for $6 \mathrm{~h}$, the PVRI decreased below baseline after the initial sympathetic storm of $\mathrm{BD}$, resulting in increased pulmonary flow and vascular congestion, contributing to increased extravascular lung water content [5]. These authors reported that the decrease in PVRI was secondary to sympathetic failure and increased vascular distensibility [5]. The data over the first $6 \mathrm{~h}$ in the present study supports these observations, replicating the early increase in SVRI and MAP, with reduction in PVRI after an early peak. Cardiac index increased from baseline, reaching a maximal value after the SVRI had dropped, resulting in a hyperdynamic circulation. This may maintain the observed reduction in PVRI via distension of pulmonary vessels and pulmonary capillary reserve recruitment [29], in addition to the loss of sympathetic vasoconstriction.

Pulmonary interstitial oedema did not differ between groups. The lack of oedema between the groups may be due to resolution of excess lung water by the end of the protocol. Skilled management likely influenced this outcome; fluid balance was similar between groups, thus preventing iatrogenic pulmonary oedema. The influence of duration of care was posited by Avlonitis et al., who observed that, in a prolonged rat model of brain death ( $15 \mathrm{~min}$ vs $5 \mathrm{~h}$ ), longer duration of care was associated with better oxygenation and reduced post-transplant PVR despite greater exposure to inflammatory cytokines [3]. This group postulated that the improvement in donor oxygenation at $4 \mathrm{~h}$ reflected clearance of neurogenic pulmonary oedema [3]. This finding was replicated in our study, demonstrating impaired oxygenation for the first $2 \mathrm{~h}$, with subsequent recovery to levels similar to controls. Duration of BD donor care also influences recipient survival in humans; time from $B D$ to cold preservation greater than $10 \mathrm{~h}$ is associated with a survival advantage at both 5 and 10 years [4]. Hormone resuscitation may have also contributed to the observed effect; methylprednisolone administration reduces extravascular lung water in BD donors [39]. Furthermore, dopamine stimulates alveolar fluid clearance and is another possible mechanism to explain our findings [40].

Whilst the absolute values of mPAP did not greatly exceed the defined cut-off for pulmonary hypertension $(>25 \mathrm{mmHg}$ ) [41] in the present study, the increased pressure was significantly greater than baseline and does reflect greater resistance that needs to be overcome by a damaged myocardium. The observation that mPAP was elevated at $24 \mathrm{~h}$ suggests that the effect of BD on pulmonary pressures may be greater than previously identified. Extended elevations in right ventricular afterload may contribute to the previously identified right ventricular ischaemia and fibrosis, further priming the right ventricle for acute failure in the recipient. Optimisation of ventilation, oxygenation and $\mathrm{pH}$ prevented contributions of these factors to the observed increase in pulmonary pressures in the current study.

Administration of catecholamines to the BD animals did represent a difference in care between the two groups. However, this is unlikely to explain the observed findings, because elevated pulmonary pressures remained unchanged when doses of vasopressors 
were decreased after commencement of hormone therapy. The use of vasoactive agents is common in BD donors [42] and has been demonstrated to reduce inflammation associated with hypotension and resultant poor tissue perfusion [38]. Previous studies of noradrenaline and dopamine infusions in sheep do not support that these agents were causative of the observed alterations in pulmonary pressures [43, 44]. In a study of noradrenaline infusion in healthy and endotoxaemic sheep, Lange et al. observed an increase in PVRI in endotoxaemic sheep only [43]. Dopamine infusion in sheep has been associated with an increase in MPAP at rates significantly higher than the doses used in the current study [44, 45]. Although ET-1 can both stimulate [46] and be stimulated by catecholamines [47, 48], comparison of ET-1 and big ET-1 concentrations over time with the average hourly dose of vasoactive agents did not reveal any correlation in the current study and, therefore, does not account for the observed results.

The current study also confirms that BD induces injury in other transplantable organs in sheep. Elevation of hepatic transaminases indicates hepatocellular injury consistent with previous animal models $[49,50]$. Serum cholestatic enzyme activities did not increase over time and suggest hepatic injury was not associated with biliary obstruction.

All BD animals required management of haemodynamic collapse with vasopressors. Haemodynamic support was reduced after hormone therapy was initiated. This is in part due to the inclusion of vasopressin but may also reflect improved haemodynamics directly due to hormonal administration. Thyroid hormone may play a role in regulating anaerobic metabolism and cardiovascular stability post-BD, however the benefits of its routine administration remains controversial $[15,51]$. The current trial included hormonal resuscitation consistent with local protocols [52].

\section{Limitations of the study}

Several important limitations have been noted in this study. As previously identified, plasma sampling times may have missed very early peaks in ET-1 or big ET-1. More frequent sampling around the induction of BD in future studies will better characterise the time course of ET-1. Small numbers of animals in each group raise the possibility of type 2 error, although pre-clinical animal models have used similar numbers [18, 19]. Myoglobin and CK-MB were chosen to assess for cardiac injury in the current study. Although troponin may reflect cardiac function in the donor, the correlation between troponin levels and recipient outcome remains controversial [53]. Recently published guidelines continue to include $\mathrm{CK}$ as a biomarker in assessment of potential heart transplantation donors $[54,55]$. Although NT-proBNP has been noted as a potential marker for assessing cardiac function in potential donors [56], it is yet to be included among standard tests for donors [57]. Inflammatory cytokines have been well characterised in other animal models of BD. An ongoing challenge in developing new models is a relative paucity of validated, species-specific analytical methods. Our group continues to develop and validate ovine-specific tests $[17,58]$, and the presented model will provide a platform to further investigate cytokine expression after BD in future studies.

\section{Conclusions}

The present model replicated the clinical realities leading to delays in organ retrieval upon $\mathrm{BD}$. Haemodynamic disturbances which occur in $\mathrm{BD}$ animals have limited the 
duration of previous studies. By utilising complete haemodynamic monitoring and support in the same fashion as is applied to human donors, it is possible to maintain a BD sheep for $24 \mathrm{~h}$. Whilst sheep undergoing BD demonstrate complex haemodynamic changes similar to those seen in humans, our data also suggests that early haemodynamic and inflammatory derangements may improve over time with aggressive donor management. This reduces the urgency for organ retrieval and supports such timeframes as are frequently encountered in daily clinical practice. However, significant increases in pulmonary blood pressure may be noted up to $24 \mathrm{~h}$ after brain death. Big ET-1 and ET-1 are detectable early after BD and may contribute to the inflammatory cascade that primes allografts for post-transplant dysfunction. Endothelin-1 may also be a key factor in the induction of right ventricular dysfunction observed in cardiac transplantation. Further investigation, targeting the endothelin axis, may provide a novel management option in order to improve the condition of transplantable hearts and lungs, increasing the number and quality of allografts available.

\section{Additional file}

Additional file 1: Additional file for the investigation of the endothelin axis and associated prolonged cardiopulmonary dysfunction and organ injury in a novel 24-h ovine model of brain death. Detailed explanation of the protocol used for animal management in development of this novel, clinically relevant, 24-h ovine model of brain death. Detailed description of immunohistochemical staining procedure. Summary of ventilation, blood gas, fluid management and haemodynamic variables over the duration of the study. Summary of biochemical data from the COBAS assessment. Summary of haematoxylin and eosin/immunohistochemical staining results. Representative images of immunohistochemical staining of the endothelin axis. (DOCX $4977 \mathrm{~kb}$ )

\section{Abbreviations}

ABG: arterial blood gas; ANOVA: analysis of variance; BD: brain death; Big ET-1: pro-endothelin-1; BIT: brain death induction time; BSA: body surface area; CFAS: calibrator for automated systems; Cl: cardiac index; CK-MB: creatine kinase MB fraction; CPP: cerebral perfusion pressure; EDTA: ethylenediaminetetraacetic acid; ET: endothelin;

$E T_{R} A$ : endothelin A receptor; $E T_{R} B$ : endothelin $B$ receptor; $F_{i} \mathrm{O}_{2}$ : fraction of inspired oxygen; ICP: intracranial pressure; LVSWI: left ventricular stroke work index; MAP: mean arterial pressure; MMP: matrix metalloproteinase; mPAP: mean pulmonary artery pressure; $\mathrm{P}(\mathrm{A}-\mathrm{a}) \mathrm{O}_{2}$ : alveolar-arterial oxygen gradient; $\mathrm{PaCO}_{2}$ : arterial carbon dioxide partial pressure; $\mathrm{PaO}_{2}$ : arterial oxygen partial pressure; PAOP: pulmonary arterial occlusion pressure; PST: protocol start time; PVRI: pulmonary vascular resistance index; RVSWI: right ventricular stroke work index; SVI: stroke volume index; $\mathrm{SVO}_{2}$ : mixed central venous oxygen saturation; SVRI: systemic vascular resistance index; TBS: tris-buffered saline; TBS-T: tris-buffered saline with triton; TIMP: tissue inhibitor of metalloproteinases.

\section{Competing interests}

The authors declare that they have no competing interests.

\section{Authors' contributions}

RPW participated in all aspects of the study and wrote the manuscript. IB contributed to laboratory analysis of biochemical and histological data. SD and KRD assisted and performed animal experiments. AGB undertook statistical analysis of physiological data and provided advice on other statistical work. ACB participated in biochemical analysis and manuscript development. JFF conceived and designed the study and provided oversight and direction. All authors read and approved the final manuscript.

\section{Acknowledgements}

This study was supported by funding provided by Roche Australia's Cellcept Australia Research Grant and The Prince Charles Hospital Foundation New Investigator Grant. Prof. John Fraser is supported by the Health Research Fellowship funded by Queensland Health. We kindly thank Jurox Australia for donation of alfaxalone for anaesthesia and also Dr. Kirby Pasloske for technical animal anaesthetic advice. Special thanks to Elissa Milford, Scott Temple, Ben Anderson, Michael Manning, Jonathon Taylor and Sue Christie for their assistance with the animal protocols. Thank you to Margaret Passmore for her guidance with the histological investigations and to Daniel Kilburn for assistance with slide preparation. We also thank Phillip Rumballe from The Prince Charles Hospital Pharmacy Department and the staff of the Medical Engineering Research Facility for their assistance.

\section{Author details}

${ }^{1}$ Critical Care Research Group, The Prince Charles Hospital, Chermside, Queensland, Australia. ${ }^{2}$ Heart Foundation Research Centre, Griffith Health Institute, Griffith University, Southport, Queensland, Australia. ${ }^{3}$ Institute of Health and Biomedical Innovation, Queensland University of Technology, Brisbane, Queensland, Australia. ${ }^{4}$ University of Queensland, Brisbane, Queensland, Australia. ${ }^{5}$ Royal Brisbane and Women's Hospital, Herston, Queensland, Australia. 
Received: 28 May 2015 Accepted: 13 November 2015

Published online: 24 November 2015

\section{References}

1. Bansal R, Esan A, Hess D, Angel LF, Levine SM, George T, Raoof S (2014) Mechanical ventilatory support in potential lung donor patients. Chest 146(1):220-227. doi:10.1378/chest.12-2745

2. Watts RP, Thom O, Fraser JF (2013) Inflammatory signalling associated with brain dead organ donation: from brain injury to brain stem death and posttransplant ischaemia reperfusion injury. J Transplant 2013:19. doi:10.1155/2013/521369

3. Avlonitis VS, Wigfield CH, Golledge HDR, Kirby JA, Dark JH (2007) Early hemodynamic injury during donor brain death determines the severity of primary graft dysfunction after lung transplantation. Am J Transplant 7(1):83-90. doi:10.1111/j.1600-6143.2006.01593.x

4. Wauters S, Verleden GM, Belmans A, Coosemans W, De Leyn P, Nafteux P, Lerut T, Van Raemdonck D (2011) Donor cause of brain death and related time intervals: does it affect outcome after lung transplantation? Eur J Cardiothorac Surg 39(4):e68-e76

5. Bittner HB, Kendall SWH, Chen EP, Craig D, Van Trigt P (1995) The effects of brain death on cardiopulmonary hemodynamics and pulmonary blood flow characteristics. Chest 108(5):1358-1363. doi:10.1378/chest.108.5.1358

6. OPTN/SRTR 2012 Annual Data Report (2014) Organ Procurement and Transplantation Network (OPTN) and Scientific Registry of Transplant Recipients (SRTR). Department of Health and Human Services, Health Resources and Services Administration, Rockville

7. Jewell AN, Swamydas M, Castillo Cl, Wyan H, Allen LD, McDermott KA, Eddy JM, Dreau D (2010) The endothelin axis stimulates the expression of pro-inflammatory cytokines and pro-migratory molecules in breast cancer. Cancer Invest 28(9):932-943. doi:10.3109/07357907.2010.496757

8. Sutherland A, Ware R, Winterford C, Fraser J (2007) The endothelin axis and gelatinase activity in alveolar macrophages after brain-stem death injury: a pilot Study. J Heart Lung Transplant 26:1040-1047

9. Comellas AP, Briva A (2009) Role of endothelin-1 in acute lung injury. Transl Res 153(6):263-271

10. Kuklin V, Kirov K, Evgenov O, Sovershaev M, Sjoberg J, Kirova S, Bjertnaes L (2004) Novel endothelin receptor antagonist attenuates endotoxin-induced lung injury in sheep. Crit Care Med 32:766-773

11. Fagan KA, McMurtry IF, Rodman DM (2001) Role of endothelin-1 in lung disease. Respir Res 2(2):90-101

12. Salama M, Andrukhova O, Hoda MA, Taghavi S, Jaksch P, Heinze G, Klepetko W, Aharinejad S (2010) Concomitant endothelin-1 overexpression in lung transplant donors and recipients predicts primary graft dysfunction. Am J Transplant 10(3):628-636. doi:10.1111/j.1600-6143.2009.02957.x

13. Bittner HB, Kendall SW, Campbell KA, Montine TJ, Van Trigt P (1995) A valid experimental brain death organ donor model. J Heart Lung Transplant 14(2):308-317

14. Oishi Y, Nishimura Y, Tanoue Y, Kajihara N, K-i I, Morita S, Yasui H (2005) Endothelin-1 receptor antagonist prevents deterioration of left ventricular function and coronary flow reserve in brain-dead canine heart. J Heart Lung Transplant 24(9):1354-1361

15. Ferrera R, Ovize M, Claustrat B, Hadour G (2005) Stable myocardial function and endocrine dysfunction during experimental brain death. J Heart Lung Transplant 24(7):921-927

16. Seok J, Warren HS, Cuenca AG, Mindrinos MN, Baker HV, Xu W, Richards DR, McDonald-Smith GP, Gao H, Hennessy L, Finnerty CC, Lopez CM, Honari S, Moore EE, Minei JP, Cuschieri J, Bankey PE, Johnson JL, Sperry J, Nathens AB, Billiar TR, West MA, Jeschke MG, Klein MB, Gamelli RL, Gibran NS, Brownstein BH, Miller-Graziano C, Calvano SE, Mason PH, Cobb JP, Rahme LG, Lowry SF, Maier RV, Moldawer LL, Herndon DN, Davis RW, Xiao W, Tompkins RG (2013) Genomic responses in mouse models poorly mimic human inflammatory diseases. Proc Natl Acad Sci U S A 110(9):3507-3512. doi:10.1073/pnas.1222878110

17. Chemonges S, Tung JP, Fraser JF (2014) Proteogenomics of selective susceptibility to endotoxin using circulating acute phase biomarkers and bioassay development in sheep: a review. Proteome Sci 12(1):12. doi:10.1186/ 1477-5956-12-12

18. Zhai W, Feng R, Huo L, Li J, Zhang S (2009) Mechanism of the protective effects of N-acetylcysteine on the heart of brain-dead Ba-Ma miniature pigs. J Heart Lung Transplant 28(9):944-949

19. Sereinigg M, Stiegler P, Puntschart A, Seifert-Held T, Zmugg G, Wiederstein-Grasser I, Marte W, Marko T, Bradatsch A, Tscheliessnigg K, Stadlbauer-Kollner V (2012) Establishing a brain-death donor model in pigs. Transplant Proc 44(7):2185-2189. doi:10.1016/j.transproceed.2012.07.105

20. Entrican G, Wattegedera SR, Griffiths DJ (2015) Exploiting ovine immunology to improve the relevance of biomedical models. Mol Immunol 66(1):68-77, http://dx.doi.org/10.1016/j.molimm.2014.09.002

21. Takao K, Miyakawa T (2014) Genomic responses in mouse models greatly mimic human inflammatory diseases. Proc Natl Acad Sci U S A. doi:10.1073/pnas.1401965111

22. Milani-Nejad N, Janssen PM (2014) Small and large animal models in cardiac contraction research: advantages and disadvantages. Pharmacol Ther 141(3):235-249. doi:10.1016/j.pharmthera.2013.10.007

23. Scheerlinck J-PY, Snibson KJ, Bowles VM, Sutton P (2008) Biomedical applications of sheep models: from asthma to vaccines. Trends Biotechnol 26(5):259-266. doi:10.1016/j.tibtech.2008.02.002

24. Hein WR, Griebel PJ (2003) A road less travelled: large animal models in immunological research. Nat Rev Immunol 3(1):79-84

25. Tung JP, Fraser JF, Wood P, Fung YL (2009) Respiratory burst function of ovine neutrophils. BMC Immunol 10:25. doi:10.1186/1471-2172-10-25

26. Mariassy AT, Glassberg MK, Salathe M, Maguire F, Wanner A (1996) Endothelial and epithelial sources of endothelin-1 in sheep bronchi. Am J Physiol 270(1 Pt 1):L54-L61

27. Van der Velden J, Snibson KJ (2011) Airway disease: the use of large animal models for drug discovery. Pulm Pharmacol Ther 24(5):525-532. doi:10.1016/j.pupt.2011.02.001

28. Kumar S, Oishi PE, Rafikov R, Aggarwal S, Hou Y, Datar SA, Sharma S, Azakie A, Fineman JR, Black SM (2013) Tezosentan increases nitric oxide signaling via enhanced hydrogen peroxide generation in lambs with surgically induced acute increases in pulmonary blood flow. J Cell Biochem 114(2):435-447. doi:10.1002/jcb.24383 
29. Novitzky D, Wicomb WN, Rose AG, Cooper DK, Reichart B (1987) Pathophysiology of pulmonary edema following experimental brain death in the chacma baboon. Ann Thorac Surg 43(3):288-294

30. ANZDATA Registry Report 2012 (2013) ANZDATA Registry. Australia and New Zealand Dialysis and Transplant Registry, Adelaide

31. Nataatmadja M, Passmore M, Russell FD, Prabowo S, Corley A, Fraser JF (2014) Angiotensin receptors as sensitive markers of acute bronchiole injury after lung transplantation. Lung 192(4):563-569. doi:10.1007/s00408-014-9588-3

32. Diggle P, Heagerty P, Liang K-L, Zeger SL (2002) Analysis of longitudinal data. Oxford University Press Inc, New York

33. Parker JD, Thiessen JJ, Reilly R, Tong JH, Stewart DJ, Pandey AS (1999) Human endothelin-1 clearance kinetics revealed by a radiotracer technique. J Pharmacol Exp Ther 289(1):261-265

34. Wagner OF, Christ G, Wojta J, Vierhapper H, Parzer S, Nowotny PJ, Schneider B, Waldhäusl W, Binder BR (1992) Polar secretion of endothelin-1 by cultured endothelial cells. J Biol Chem 267(23):16066-16068

35. Dupuis J, Goresky CA, Fournier A (1996) Pulmonary clearance of circulating endothelin-1 in dogs in vivo: exclusive role of ETB receptors. J Appl Physiol 81(4):1510-1515

36. Salama M, Andrukhova O, Jaksch P, Taghavi S, Kelpetko W, Dekan G, Aharinejad S (2011) Endothelin-1 governs proliferation and migration of bronchoalveolar lavage-derived lung mesenchymal stem cells in bronchiolitis obliterans syndrome. Transplantation 92(2):155-162

37. Salama M, Jaksch P, Andrukhova O, Taghavi S, Klepetko W, Aharinejad S (2010) Endothelin-1 is a useful biomarker for early detection of bronchiolitis obliterans in lung transplant recipients. J Thorac Cardiovasc Surg 140(6):1422-1427

38. Avlonitis VS, Wigfield CH, Kirby JA, Dark JH (2005) The hemodynamic mechanisms of lung injury and systemic inflammatory response following brain death in the transplant donor. Am J Transplant 5(4):684-693

39. Venkateswaran RV, Patchell VB, Wilson IC, Mascaro JG, Thompson RD, Quinn DW, Stockley RA, Coote JH, Bonser RS (2008) Early donor management increases the retrieval rate of lungs for transplantation. Ann Thorac Surg 85(1):278-286

40. Ware LB, Fang X, Wang Y, Sakuma T, Hall TS (1985) Matthay MA (2002) Selected contribution: mechanisms that may stimulate the resolution of alveolar edema in the transplanted human lung. J Appl Physiol 93(5):1869-1874. doi:10.1152/japplphysiol.00252.2002

41. Chemla D, Castelain V, Herve P, Lecarpentier Y, Brimioulle S (2002) Haemodynamic evaluation of pulmonary hypertension. Eur Respir J 20(5):1314-1331

42. Dare A, Bartlett A, Fraser J (2012) Critical care of the potential organ donor. Curr Neurol Neurosci Rep 12(4):456-465 doi:10.1007/s11910-012-0272-9

43. Lange M, Broking K, Hucklenbruch C, Ertmer C, Van Aken H, Lucke M, Bone HG, Westphal M (2007) Hemodynamic effects of titrated norepinephrine in healthy versus endotoxemic sheep. J Endotoxin Res 13(1):53-57. doi:10.1177/ 0968051907078614

44. Feltes TF, Hansen TN, Martin CG, Leblanc AL, Smith S, Giesler ME (1987) The effects of dopamine infusion on regional blood flow in newborn lambs. Pediatr Res 21(2):131-136. doi:10.1203/00006450-198702000-00005

45. Teboul JL, Douguet D, Mercat A, Depret J, Richard C, Zelter M (1998) Effects of catecholamines on the pulmonary venous bed in sheep. Crit Care Med 26(9):1569-1575

46. Boarder MR, Marriott DB (1991) Endothelin-1 stimulation of noradrenaline and adrenaline release from adrenal chromaffin cells. Biochem Pharmacol 41(4):521-526

47. Morimoto T, Hasegawa K, Wada H, Kakita T, Kaburagi S, Yanazume T, Sasayama S (2001) Calcineurin-GATA4 pathway is involved in beta-adrenergic agonist-responsive endothelin-1 transcription in cardiac myocytes. J Biol Chem 276(37):34983-34989. doi:10.1074/jbc.M005498200

48. Yanagisawa M, Kurihara H, Kimura S, Tomobe Y, Kobayashi M, Mitsui Y, Yazaki Y, Goto K, Masaki T (1988) A novel potent vasoconstrictor peptide produced by vascular endothelial cells. Nature 332(6163):411-415

49. Hoti E, Levesque E, Sebagh M, Heneghan HM, Khalfallah M, Castaing D, Azoulay D (2014) Liver transplantation with grafts from donors who die from suicide by hanging: a matched cohort study. Transplantation 98(11):1236-1243

50. Zhu C, Li J, Zhang G, Zhang Y, Zhai W, Shi J, Li Z, Zhang S (2010) Brain death disrupts structure and function of pig liver. Transplant Proc 42(3):733-736

51. Macdonald PS, Aneman A, Bhonagiri D, Jones D, O'Callaghan G, Silvester W, Watson A, Dobb G (2012) A systematic review and meta-analysis of clinical trials of thyroid hormone administration to brain dead potential organ donors. Crit Care Med 40(5):1635-1644

52. National Guidelines for Organ and Tissue Donation 4th Edition (2008) Australasian transplant coordinators association incorporated, organ and tissue authority Australia

53. Dronavalli VB, Banner NR, Bonser RS (2010) Assessment of the potential heart donor: a role for biomarkers? J Am Coll Cardiol 56(5):352-361. doi:10.1016/j.jacc.2010.02.055

54. Kilic A, Emani S, Sai-Sudhakar CB, Higgins RSD, Whitson BA (2014) Donor selection in heart transplantation. J Thoracic Dis 6(8):1097-1104. doi:10.3978/j.issn.2072-1439.2014.03.23

55. Organ Procurement and Transplantation Network (2015) Policy 2: Deceased Donor Organ Procurement. http:// optn.transplant.hrsa.gov/governance/policies/. Accessed 3 August 2015

56. Dronavalli VB, Ranasinghe AM, Venkateswaran RJ, James SR, McCabe CJ, Wilson IC, Mascaro JG, Bonser RS (2010) $\mathrm{N}$-terminal pro-brain-type natriuretic peptide: a biochemical surrogate of cardiac function in the potential heart donor. Eur J Cardiothorac Surg 38(2):181-186. doi:10.1016/j.ejcts.2010.01.024

57. Costanzo MR, Dipchand A, Starling R, Anderson A, Chan M, Desai S, Fedson S, Fisher P, Gonzales-Stawinski G, Martinelli L, McGiffin D, Smith J, Taylor D, Meiser B, Webber S, Baran D, Carboni M, Dengler T, Feldman D, Frigerio M, Kfoury A, Kim D, Kobashigawa J, Shullo M, Stehlik J, Teuteberg J, Uber P, Zuckermann A, Hunt S, Burch M, Bhat G, Canter C, Chinnock R, Crespo-Leiro M, Delgado R, Dobbels F, Grady K, Kao W, Lamour J, Parry G, Patel J, Pini D, Towbin J, Wolfel G, Delgado D, Eisen H, Goldberg L, Hosenpud J, Johnson M, Keogh A, Lewis C, O'Connell J, Rogers J, Ross H, Russell S, Vanhaecke J (2010) The International Society of Heart and Lung Transplantation Guidelines for the care of heart transplant recipients. J Heart Lung Transplant 29(8):914-956. doi:10.1016/j.healun. 2010.05.034

58. Passmore M, Nataatmadja M, Fraser JF, Passmore M, Nataatmadja M, Fraser JF (2009) Selection of reference genes for normalisation of real-time RT-PCR in brain-stem death injury in Ovis aries. BMC Mol Biol 10:72 